\title{
Environmental and Economic Role of the Lean Production in Transition to Sustainable Development
}

\author{
Mark Anastasov ${ }^{1}$, Nina Kazitskaya ${ }^{1}$, and Irina Politkovskaya ${ }^{1}$ \\ ${ }^{1}$ Moscow Automobile and Road Construction State Technical University (MADI), 125319, 64 \\ Leningradsky av., Moscow, Russia
}

\begin{abstract}
The concept of "lean production" today is one of the most effective strategic measures for the transition to sustainable development. It is aimed primarily at the initiation of resource-saving technologies at the micro level of production, and gradually takes a global character, turning from a tool of progressive organization of production into harmonization of an everexpanding industry and environment. This concept is particularly relevant in the context of sustainable development policies that are currently being implemented in technologically advanced countries. However, the uneven economic development of the territories and the high level of differentiation in the technological and socio-economic development of different countries and regions necessitate the creation of new clusters of lean production based on the competitive advantages of the regions. The success of the implementation of sustainable development policies in any country depends largely on how effectively business leaders are aware of the need to invest in resource-saving technologies and use lean production mechanisms designed to reduce overspending of natural resources.
\end{abstract}

\section{Introduction}

Environmental management is systemically related to production and is included in the overall enterprise management system. Therefore, production management, which is based on saving resources, organically consists of controlling the financial, industrial and environmental spheres, and manifests itself in the conscious human influence on natural, technological and social processes, as well as environmental objects to meet public economic, cultural and other needs. Environmental management is regulated by the Russian GOST 2452-80, European standards EMAS, BS7750, International Organization for Standardization ISO 14000 [1-3].

\section{Materials and Methods}

In accordance with ISO 14004, the basic principles of a lean environmental management system are:

1. Establishment of the order in which environmental management becomes one of the company's priorities. 
2. Creating or strengthening the company's environmental services.

3. Establishment and maintenance of relations with internal and external stakeholders devoted to effective environmental policy (including society).

4. Implementing an agreement between management and environmental officers with a mutual understanding of environmental responsibility.

5. Compliance with the requirements of regulatory environmental aspects of the company and clarifying the compliance of environmental impact indicators with acceptable standards.

6. Initial assessment of production parameters and other processes necessary to achieve the required level of environmental performance of the enterprise.

7. Incorporate procedures for planning and integrating environmental aspects throughout the product or service life cycle.

8. The distribution of material, financial and human resources sufficient to ensure the chosen level of environmental safety.

9. Evaluation of management processes through auditing and determining the feasibility of improving the environmental management system.

10. Implementation and development of subsystems of environmental marketing, engineering, environmental education.

Consequently, it is the production process where the ecological role of technologies of resource consumption is being formed. In turn, the main task of the production system is to continuously improve the so-called "value stream" for the target audience. Its basis is a rational combination of all processes. Due to this, products can be produced with minimal expenditure of natural resources, if the technologies of its production are sufficiently intensive and progressive. In addition, the greening of production technologies has an important economic effect, affecting the financial and investment indicators and the results of production and economic activities of enterprises, including total costs, profitability of production, profits, working capital.

At the same time, for many mining and machinery enterprises, the most important is the question of the efficiency of production processes from the standpoint of environmental efficiency and the conditionality of the production cycle using recycled waste and recycling of natural resources [4-6]. To solve the problem of reducing the production cycle as the use of environmental protection technologies expands, many enterprises are introducing a lean manufacturing system in their operations that allows to optimize the production process, improve the environmental friendliness of the products being produced and reduce the consumption of non-renewable natural resources.

Lean manufacturing (production) is a special approach to the management of an enterprise, which allows to improve economic performance in the process of reducing losses in the form of non-returnable industrial waste, especially of mineral and natural origin. In economics, losses mean everything that reduces the efficiency of enterprises. The main types of losses considered in the lean manufacturing research include [7-8]:

- movements (unnecessary replacement of equipment and operators, leading to an increase in the cost of electricity and, accordingly, increase in the cost of products);

- transportation (unnecessary movement, leading to increased energy consumption, damage and loss of the finished product with resource overuse);

- technology (technological shortcomings that do not allow to realize all the useful properties of raw materials in the product);

- overproduction (unsold products that require extra costs for accounting, storage, as well as leading to the wasting of natural resources);

- waiting (not finished products, waiting for the queue for processing and increasing the cost);

- defects (any defects resulting in additional product losses);

- stocks (surplus of finished products). 
The lean manufacturing system was developed at the turn of the 1980s-1990s by Japanese engineers Taichi Ono and Shigeo Shingo (since Japan is a mineral deficient, saving material resources is always of paramount importance) [9]. The goal of the engineers was to reduce actions that do not add value to the product during its entire life cycle, and to reduce technological losses of resources. Thus, the system of lean production is not just a technology, but also a whole management concept with maximum production focus on the environmental requirements of consumers and society, which are closely related to economic efficiency.

The experience gained in implementing a lean manufacturing system in various countries of the world (sometimes its individual elements) in the routines of various organizations has shown its efficiency and prospects, and is currently used in various industries. If initially the system was used only at automobile plants "Toyota", "Honda", etc. (and was called the Toyota Production System), then today it is found in many other areas: medicine, trade, logistics, mining, education, construction. Many enterprises of these industries receive additional market advantages and economic benefits, positioning themselves as leaders of lean manufacturing and resource-saving manufacturers [10].

\section{Results and Discussion}

The main principles of lean production, which determine their role in the transition of modern industry to sustainable development, are the following:

1. The principle of consistency. In accordance with it, manufacturing processes are the elements of the industrial production system in the cluster and further elements of the entire ecological and economic system, which includes, besides material production and other human activities, the natural environment (populations of living organisms, atmosphere, hydrosphere, lithosphere, ), as well as man and his habitat. Therefore, when creating lean production, it is necessary to take into account the existing and increasing interconnection and interdependence of production, social and natural processes.

2. Comprehensive use of resources. This principle of creating lean production requires the maximum use of all components of raw materials and the potential of energy resources. As is known, almost all raw materials are complex in composition. On average, more than a third of its quantity consists of accompanying elements, which can be extracted only with the complex processing of raw materials. Thus, complex processing of polymetallic ores makes it possible to produce about 40 elements in the form of high-purity metals and their compounds. Already at present almost all silver, bismuth, platinum and platinum metals, as well as more than $20 \%$ of gold, are obtained along with complex processing of polymetallic ores [2].

3. Cyclical material flows. This is a general principle of creating lean production. Examples of cyclical material flows are closed water and gas circulation cycles. The consistent application of this principle should ultimately lead to the formation of organized and regulated man-made circulation of matter and associated energy conversions, first in individual clusters, and subsequently in the whole technosphere.

4. Limiting and eliminating the harmful effects of production on the biosphere with a planned and targeted increase in lean production. This principle is obliged to ensure the preservation of natural and economic resources such as air, water, surface of the earth, public health. This principle is feasible only in combination with effective monitoring, developed environmental regulation and multi-tier environmental management.

5. The rationality of lean production: reasonable use of all components of raw materials; minimization of energy, material and labor intensity of production; search for new environmentally sound raw materials and energy technologies that eliminate or reduce the harmful effects on the biosphere; production cooperation with the use of waste of some industries as a raw material for others. 
When creating lean production by improving existing and developing new technological processes, the following methods should be implemented:

- performing the production processes with the minimum possible number of technological stages (apparatuses), since losses are generated at each of them;

- an increase in unit capacity of the units, the use of continuous processes; intensification of production processes, their optimization and automation;

- creation processes that combine energy with technology. Power-producing technological processes make it possible to more fully utilize the energy of chemical transformations, save energy resources, raw materials and materials, and increase the total productivity.

Based on the analysis of the methodology and practical experience in applying lean manufacturing technologies at the global and national levels, we have identified the following main tools for lean manufacturing:

1. Standardized works. They are a clear and highly visualized algorithm for the implementation of any specific elements of the technology. This algorithm includes different standards, for example, the standards of environmental friendliness of the products produced, the duration of the production cycle, standards of the sequence of actions during one cycle, environmental standards of materials, etc.

2. SMED (Single Minute Exchange of Details). This is a special technology of fast equipment changeover. As a rule, two categories of operations are used for readjustment. The first is external operations, and they can be carried out without stopping the equipment (this includes the preparation of materials and tools, etc.). The second is the operation is internal, and for their implementation the equipment must be stopped. The meaning of SMED is that the maximum number of internal operations is transferred to external ones. This is achieved through organizational and technological innovation. The SMED system allows you to minimize resource consumption when using efficient equipment.

3. Pulling production. Approach to the organization of the production flow, which eliminates losses associated with waiting (until the previous stage of work is completed) and overproduction. Here, each process operation "pulls" the required volume of product from the previous operation and then transfers the next one. This allows you to avoid the appearance and surplus of the product and the overrun of natural resources.

4. The system of submission and consideration of proposals. According to it, any employee can offer their ideas to improve the workflow. All employees are provided with a clear mechanism for the implementation of their proposals. The system also includes methods of encouraging employees to offer their ideas, to improve the environmental friendliness of production.

5. Method "Breakthrough to flow." It is used to equalize and increase the efficiency of the production flow. For this purpose, fixed production cycles are created, in each of which the principles of standardized work are implemented.

6. TPM (Total Productive Maintenance) - the system of universal service equipment. When using it, equipment operation is combined with its ongoing maintenance. Such continuous monitoring and maintenance of equipment in good condition are provided by qualified staff. With the help of TPM, it is possible to reduce the level of losses associated with repairs, downtime and breakdowns, and to ensure maximum efficiency during the entire life cycle of the equipment. Another plus is that the staff gets time to solve other tasks.

7. System $5 \mathrm{~S}$ is a management methodology that allows you to efficiently organize your work space. The abbreviation hides the following concepts:

- Systematization (all items are in a specific place where there is easy access);

- Sweeping - keeping order and cleanliness;

- Sorting (documentation and / or items are located in the workplace, based on the frequency of their use; this also includes the elimination of everything that is no longer needed);

- Standardization (workplaces are organized according to the same principle); 
- Set in Order improvement (established standards and principles are constantly being improved).

As for Russian companies specifically, lean technologies in their work today are used by Rusal, Expert Volga LLC, Signal EPO, Khlebprom OJSC VSMPO-AVISMA, KAMAZ PJSC, Oriflame Cosmetics LLC. TekhnoNIKOL LLC, PG Group Gas, LLC EuroChem and dozens of other major organizations. According to the Expert Media holding, Russia began to introduce lean production only in 2004. And by 2007 (in just three years of practice), the system showed impressive results. And there is more than one example:

The consumption of natural resources in the fields of oil production, instrument-making, car assembly has decreased by $30 \%$.

$30 \%$ freed up production space in the field of instrumentation.

Incomplete production in the field of oil production decreased by $50 \%$.

The production cycle in the areas of instrument-making and the aviation industry has decreased by $60 \%$.

The efficiency of equipment in the field of non-ferrous metallurgy increased by $45 \%$.

$25 \%$ freed labor resources in the field of oil production.

The changeover time in the steel industry has decreased by $70 \%$.

Such an increase in efficiency and a reduction in the material consumption of production lays the foundation for reducing the negative impact of the booming manufacturing industry on the environment. This creates the material basis for the transition to sustainable development in the process of the fourth scientific and technological revolution, which began from the early 21 st century. The specific foundation for sustainable development is created due to the following positive environmental effects from the development of lean production:

1) Reduced resource consumption. On the example of the largest European holding companies, it can be seen that the introduction of lean manufacturing has saved $30-70 \%$ of resources, because the company has moved from mass production to a stream of single products. In addition, the production itself has changed. Cross-functional approach has also led to a reduction in the cost of raw materials, energy, working time. Due to the fact that the workspace was used more efficiently, reduced transportation of products, reduced defects, improved energy efficiency. In addition, stocks have decreased, so that they do not lie in stock for a long time and thus do not increase the company's costs. For example, in Auburn, savings from a more rational use of raw materials by Boeing amounted to 22 million dollars, and the introduction of a recycling system for the production of panels for Boeing 747 wings at the Everett plant saved 10 cubic meters of cardboard and protective packaging.

2) Reduced industrial waste. A large number of costs in the company also goes to the disposal of industrial waste. The lean manufacturing system reduces this waste by instilling in employees the idea that it is necessary to save resources and constantly evaluate costs in production processes. Such a philosophy should become a part of the corporate culture. In addition, it is necessary to recycle waste or reuse it. Only continuous improvement and responsible approach will reduce industrial waste to a minimum.

3) Production of industrial companies are becoming more environmentally friendly. Environmental conditions, as is known, deteriorate over time, so the state requires industrial companies to be responsible for their production in terms of its impact on the environment. Some industries do a lot of damage to the environment, and lean manufacturing technology is developing ways to protect the environment, but at the same time that the company has financial benefits. For this, raw materials are spent more efficiently and energy efficiency is increased. In some countries, there are heavy fines for high resource consumption and frequent emissions of unsafe substances. Lean manufacturing technology avoids the payment of these fines, since consumption is reduced and the emission of harmful substances also becomes less. 


\section{Conclusion}

Thus, the development of lean manufacturing technologies allows us to solve two interrelated tasks directly related to the transition to sustainable development: to increase industrial output and reduce the burden on the environment. These tasks were unsolvable together in the complex of traditional industry technologies that were active at the beginning of the 20th century. However, in the transition to lean production, it is possible to combine accelerated industrial and economic growth and reduce the anthropogenic impact on the environment, avoid depletion of irreversibly used non-renewable natural resources.

\section{References}

1. S.A. Zhironkin, K.A. Kolotov, A.E. Genin, F.V. Agafonov, S.A. Kovalevsky, IOP Conf. Ser.: Earth Environ. Sci., 50:1, 012011 (2017)

2. S. Zhironkin, S. Demchenko, G. Kayachev, M. Ryzhkova, O. Zhironkina, E3S Web Conf., 41, 04011 (2018)

3. M. Tyulenev, O. Litvin, M. Cehlár, S. Zhironkin, M. Gasanov, Acta Montanistica Slovaca, 22:3, 296-302 (2017)

4. O. Litvin, M. Tyulenev, S. Zhironkin, S. Prokopenko, Acta Montanistica Slovaca, 22:2, 146152 (2017)

5. S. Zhironkin, M. Gasanov, G. Barysheva, K. Kolotov, O. Zhironkina, E3S Web Conf., 15, 03012 (2017)

6. M.A. Tyulenev, S.A. Zhironkin, E.A. Garina, Int. J. Min. Miner. Eng., 7:4, 363-370 (2016)

7. I.A. Kudryashova, E.A. Kharlampenkov, N.V. Zakharova, Izvestiya Ferrous Metallurgy, 61:11, 914-919 (2018) DOI: 10.17073/0368-0797-2018-11-914-919

8. I. Kudryashova, E. Kharlampenkov, N. Zakharova, A. Kolevatova, E3S Web Conf., 41, 02025 (2018)

9. S.A. Zhironkin, K.A. Kolotov, A.E. Genin, F.V. Agafonov, S.A. Kovalevsky, IOP Conf. Ser.: Earth Environ. Sci., 50:1, 012011 (2017)

10. D. Szurgacz, J. Brodny, SGEM, 17:13, 47-54 (2017) DOI: doi.org/10.5593/sgem2017/13/S03.007 